\title{
A detection of unexpected blood antibody at the time of transfusion was needed, during the operation -A case report-
}

\author{
Hyung Joon Kim ${ }^{1}$, Yun Hee $\mathrm{Lim}^{1}$, Byung Hoon $\mathrm{Yoo}^{1}$, Seung-Hoon Woo ${ }^{1}$, Ki Hyuk Hong ${ }^{1}$, and \\ Jung Won Kim²
}

Department of Anesthesiology and Pain Medicine, ${ }^{1}$ Sanggye Paik Hospital, College of Medicine, Inje University, Seoul, ${ }^{2}$ Ilsan Paik Hospital, College of Medicine, Inje University, Goyang, Korea

To avoid the occurrence of fatal complications of blood transfusion, several tests are implemented before transfusion. The tests include ABO typing, Rh typing, cross-matching test and blood antibody screening test, and in usual they are completed before transfusion. However in the case of repetitive operations done via brief distance, reexamination for blood antibody tends to be omitted. After 2 previous operations, 30 years old male patient showed positive blood antibody screening during the third operation. Although antibody screening test performed before the first operation, no unexpected blood antibody was detected. During the third operation, after the decision to start transfusion was made, it took two hours to find appropriate blood. There was no significant deterioration of patient's condition but the loss of time could lead to critical consequences. We present this case to make anesthesiologists and surgeons aware of possibility of unexpected blood antibody detection after transfusion. (Korean J Anesthesiol 2013; 64: 65-68)

Key Words: Antibody, Complication, Transfusion.

Blood compatibility testing is necessary to prevent critical complications of blood transfusion. The American Association of Blood Banks has recommended that ABO typing, Rh typing, unexpected antibody screening, and crossmatching must be performed before a blood transfusion.

Since blood antibody screening is generally included in the list of preoperative tests, an emergency transfusion can be performed immediately in the case of intraoperative massive bleeding. However, when an emergency transfusion is required in circumstances in which the unexpected antibody screening test has not been performed, the delay while finding the compatible blood may be life-threatening.

We herein report and discuss a case in which a patient who had shown a negative response in the first preoperative unexpected antibody screening test was given a blood transfusion for intraoperative bleeding and who later required

Received: July 26, 2011. Revised: October 21, 2011. Accepted: November 7, 2011.

Corresponding author: Yun Hee Lim, M.D., Department of Anesthesiology and Pain Medicine, Sanggye Paik Hospital, Sanggye 7-dong, Nowongu, Seoul 137-707, Korea. Tel: 82-2-950-1176, Fax: 82-2-950-1323, E-mail: painfree@paik.ac.kr

C) This is an open-access article distributed under the terms of the Creative Commons Attribution Non-Commercial License (http:// creativecommons.org/licenses/by-nc/3.0/), which permits unrestricted non-commercial use, distribution, and reproduction in any medium, provided the original work is properly cited. 
a rapid emergency transfusion that was difficult to perform due to the identification of an autoantibody.

\section{Case Report}

A 30-year-old male patient was brought to our hospital with the chief complaint of abdominal pain following a traffic accident. The patient's consciousness was clear, but his vital signs showed hypotension $(66 / 43 \mathrm{mmHg})$, tachycardia (heart rate 109 beats per minute), and hyperventilation, indicating hypovolemic shock. Blood testing performed in the emergency room revealed hemoglobin $(\mathrm{Hb}) 8.6 \mathrm{~g} / \mathrm{dl}$ and hematocrit (Hct) 26.3\%. The abdominal computed tomography (CT) showed pancreatic head injury and active bleeding, and an emergency exploratory laparotomy was performed under the diagnosis of hemoperitoneum. The patient had no particular medical history except for taking medication for rheumatic heart disease 17 years earlier, and he had never undergone surgery.

Preoperative blood testing performed in the emergency room showed a negative result on the unexpected antibody screening test. Due to intraoperative blood loss, 11 pints of packed red blood cells and 5 pints of fresh frozen plasma were administered. A complete blood count performed immediately after the operation showed $\mathrm{Hb} 10.4 \mathrm{~g} / \mathrm{dl}$. Two additional pints of packed red blood cells were transfused one hour after the end of the operation since the Hb level was measured to be $8.1 \mathrm{~g} / \mathrm{dl}$. Including this transfusion, a total of five additional pints of packed red blood cells were transfused by the third postoperative day. The patient's body temperature was maintained over $37.5^{\circ} \mathrm{C}$ following the operation.

On the eighth day following the first operation, panperitonitis caused by duodenal perforation was found, and a second exploratory laparotomy was thus performed. Preoperative blood tests showed that $\mathrm{Hb}, \mathrm{Hct}$, and platelets (PLT) were in the normal range, but that the white blood cell (WBC) level had increased to $213,000 / \mu \mathrm{l}$. Other blood tests revealed no abnormal findings. An unexpected antibody screening test was not performed at this time. On the first day after the operation, the patient's $\mathrm{Hb}$ had decreased to $8.9 \mathrm{~g} / \mathrm{dl}$, and thus two pints of packed red blood cells were transfused. Following the transfusion, fever, with a body temperature of $37.8^{\circ} \mathrm{C}$, was found, with accompanying chills. On the second postoperative day, bleeding continued at the suture site and through the surgical drain, and the $\mathrm{Hb}$ was found to be $9.0 \mathrm{~g} / \mathrm{dl}$. One pint of packed red blood cells was transfused, but bleeding continued to be observed. On the seventh postoperative day, three pints of packed red blood cells were transfused when the patient had a $\mathrm{Hb}$ of $8.2 \mathrm{~g} / \mathrm{dl}$ with a measured body temperature over $38.2^{\circ} \mathrm{C}$. After this transfusion, the $\mathrm{Hb}$ was $9.2 \mathrm{~g} / \mathrm{dl}$, blood urea nitrogen (BUN) $8 \mathrm{mg} / \mathrm{dl}$ and creatinine $(\mathrm{Cr}) 0.8 \mathrm{mg} / \mathrm{dl}$. Jaundice or hemoglobinuria that might suggest a blood transfusion reaction was not found.

Sixty days after the first operation, a third exploratory laparotomy was performed for a chief complaint of duodenal perforation and large intestine omental laceration. The patient's vital signs at that time were blood pressure $130 / 80 \mathrm{mmHg}$, heart rate $80 / \mathrm{min}$, tidal rate $20 / \mathrm{min}$, and body temperature $37.0^{\circ} \mathrm{C}$. Blood tests showed normal findings, but a preoperative unexpected antibody screening test was not performed. During the operation, at about one and a half hours after the induction of general anesthesia, massive bleeding was found, accompanied by tachycardia, with a heart rate of 110 beats per minute or higher. At one hour and 50 minutes after the start of the operation, the diastolic blood pressure had dropped below $50 \mathrm{mmHg}$, and tachycardia, with a heart rate of 130 beats per minute or higher, was found. A volume expander (colloid) was therefore intravenously injected.

The patient's vital signs then stabilized to some extent, but the intraperitoneal bleeding continued, and the decision was made to perform a transfusion. The arterial blood gas analysis performed at that time showed $\mathrm{Hb} 8.0 \mathrm{~g} / \mathrm{dl}$, Hct 29\%, and $\mathrm{pH}$ 7.41. Crossmatching performed as the blood sample was taken and sent to the test room showed a positive antigen-antibody reaction. The unexpected antibody screening test that was performed because no appropriate blood was found repeatedly showed a positive result.

Due to these findings, it was impossible to perform a transfusion promptly, and thus both the need for rapid transfusion and the probability of reactions due to the transfusion of incompatible blood had to be taken into account at the same time. While testing was continued, the patient's systolic blood pressure was kept at $80-100 \mathrm{mmHg}$, but tachycardia persisted, with a heart rate of 130 beats per minute or higher, and the diastolic blood pressure remained at $50 \mathrm{mmHg}$, with continued bleeding observed.

A discussion was held among the surgeon, the laboratory medicine expert, and the anesthesiologist. The crossmatching testing was continued, and an antigen-antibody reaction over $2+$ was found repeatedly. Meanwhile, we found weakly positive blood with an antigen-antibody reaction of $1+$ in the 11 th sample.

Although an emergency blood transfusion was required, crossmatching had to be performed between the patient's blood and the blood to be transfused, a procedure which required two hours to find the most appropriate blood. At about five hours after the start of the operation, transfusion of five pints of packed red blood cells was begun. The patient's vital signs then stabilized, with the mean arterial pressure higher than $90 \mathrm{mmHg}$ and the diastolic blood pressure higher than 70 mmHg. The arterial blood gas analysis at the start of the blood 
transfusion showed $\mathrm{Hb} 6.2 \mathrm{~g} / \mathrm{dl}$, Hct 19.6\%, and $\mathrm{pH}$ 7.34.

The operation continued for about six additional hours, and the total blood loss was estimated to be $4000 \mathrm{ml}$. After transferring the patient to the intensive care unit (ICU), three pints of packed red blood cells and five pints of fresh frozen plasma were additionally transfused, and thus a total of eight pints of packed red blood cells were administered on the day of the operation.

During the postoperative follow-up, we found no symptoms that suggested delayed serological transfusion reaction (DSTR) or delayed hemolytic transfusion reaction. The patient was discharged after 100 days without any sequelae. The warm autoantibody adsorption test performed by the ZZAP method 90 days after the last blood transfusion verified that the unexpected antibody found in the patient was an autoantibody.

\section{Discussion}

The non-infectious complications that may occur following blood transfusion include acute immunologic hemolysis, delayed hemolytic transfusion reaction, febrile allergic transfusion reaction, and non-immunologic red blood cell hemolysis, some of which may take place even during blood transfusion $[1,2]$.

Unexpected antibodies, also called irregular antibodies, are antibodies whose existence in a person's serum cannot be known before testing is performed, and they include antibodies against such antigens as Rh, MNSs, Duffy, and Kidd [3]. Unexpected antibodies are very important clinically because they may cause critical transfusion reactions such as acute or delayed hemolytic transfusion reaction or neonate hemolytic syndrome [4].

Most medical centers implement pre-transfusion tests for safe transfusion, including ABO blood typing, RhD blood typing, and crossmatching. However, occurrence of transfusion reactions due to unexpected antibodies other than the $\mathrm{ABO}$ blood type antibody and anti-D antibody may not be predicted with only these tests, and thus an unexpected antibody screening test and identification test are necessary. Considering that unexpected antibodies are detected at a higher rate in those who have a past history of blood transfusion or pregnancy and in those who have received large volumes of blood $[5,6]$, unexpected antibody screening is generally recommended to be performed at 72-hour intervals [7]. Regarding this recommendation, insurance benefits had been limited to coverage of only one test during a treatment period, but this limitation was abolished in 2009 so that patients undergoing consecutive transfusions may be given the unexpected antibody test every third day. However, as in our case, if operations are repeated in a short interval or a relatively simple operation is planned, an unexpected antibody screening test is often omitted and the operation is performed on the basis of the previous test results, resulting in a serious problem in the preparation of blood.

Kil et al. [8] reported that blood transfusion should be avoided as much as possible in patients with hemolytic anemia who show incompatibility with all types of blood in the crossmatching test. However, Petz and Garratty $[9,10]$ emphasized that even the transfusion of blood that is incompatible in vitro should not be considered contraindicated if the anemia is life-threatening, even though it may be difficult to perform a crossmatching test and to detect isogenic antibodies because of the autoantibody.

Generally, in cases where a surgery in which blood transfusion is expected to be required due to intraoperative blood loss is planned, if an unexpected antibody is identified in the preoperative test, a screening test should be carried out to choose and prepare blood that lacks the antigen against the identified antibody. However, in cases where the compatible blood product is not available but a rapid transfusion needs to be performed urgently, a decision as to the more advantageous course of action must made, considering both the possibility of acute hemolytic transfusion reaction and the risk of delayed transfusion [9]. In our case, considering these factors in a situation in which massive bleeding continued, we performed transfusion of blood which showed an antigen-antibody reaction test result of +1 under consultation with the laboratory medicine expert and the anesthesiologist.

In our case, the body temperature of the patient had increased to $37.8^{\circ} \mathrm{C}$ or higher following the transfusion after the second surgery, a finding suspicious for occurrence of a transfusion reaction or expression of an unexpected antibody beforehand. However, the possibility of a transfusion reaction seems to be low because the fever over $37.5^{\circ} \mathrm{C}$ had continued since the first surgery and there were no signs that make us suspect any allergic transfusion reaction or hemolytic reaction. The possibility of past expression of an unexpected antibody is also low because compatible blood was easily obtained in the crossmatching test for the transfusion on the second day after the second surgery. However, since we did not perform a repeat unexpected antibody screening test in the sixty days after the first surgery, it is difficult to accurately estimate the time when the antibody was expressed.

In this case, we experienced unavoidable delay before the emergency transfusion. Fortunately, the prognosis of the patient was good, with no other signs of transfusion reaction, and thus the patient could be discharged. However, it is true that a similar case in the future may not be perfectly prevented. Some medical centers in foreign countries issue a medical alert card containing such relevant patient information for future blood transfusion so that the patient can present it when he or she is hospitalized in another medical center or undergoes blood 
transfusion [3]. Considering the circumstances in Korea, Park et al. [11] commented that it is necessary to introduce a system in which records relating to clinically important antibodies are preserved continuously so that the past record can be checked out before dispensing a red blood cell product.

In this report, we highlight the importance of repeatedly carrying out unexpected antibody screening tests. We also hope to minimize the occurrence of fatalities by performing an unexpected antibody screening test for susceptible patients regardless of the scope and severity of the planned operation.

\section{References}

1. Perrotta PL, Snyder EL. Non-infectious complications of transfusion therapy. Blood Rev 2001; 15: 69-83.

2. Kim MK, Koo BN, Kil HK, Kim KB. Acute hemolysiss caused by transfusion of overheated blood. Korean J Anesthesiol 2006; 50: 463-5.

3. Harvey GK. Transfusion in clinical medicine. 10th ed. Oxford,
Blackwell science. 1997, pp 201-2.

4. Herbert FP. Modern blood banking and transfusion practices. 4th ed. Philadelphia, F.A. Davis Co. 1999, pp 200-76.

5. Redman M, Regan F, Contreas M. A prospective study of the incidence of red cell alloimmunization Following transfusion. Vox Sang 1996; 71:216-20.

6. Walker RH, Lin DT, Hatrick MB. Alloimmunization following blood transfusion. Arch Pathol Lab Med 1989; 113: 254-61.

7. Goodnough LT. Technical manual. 14th ed. Bethesda, Maryland, American association of blood bank. 2002, pp 315-92.

8. Kil YK, Choi YJ, Cho SR, Kim HJ, Kim HO. Red blood cell transfusion in autoimmune hemolytic anemia. Korean J Clin Pathol 1997; 17: 839-46.

9. Garratty G, Petz LD. Transfusing patients with autoimmune haemolytic anaemia. Lancet 1993; 341: 1220.

10. Petz LD. Transfusing the patient with autoimmune hemolytic anemia. Clin Lab Med 1982; 2: 193-210.

11. Park TS, Chang CL, Chung JS, Cho H, Lee EY, Son HC, et al. The frequency and clinical significance of delayed serological transfusion reactions in Korean population. Korean J Blood Transfus 2005; 16: 20-31. 